\title{
CFD-Guided Development of Test Rigs for Studying Erosion and Large-Particle Damage of Thermal Barrier Coatings
}

\author{
Maria A. Kuczmarski, Robert A. Miller, and Dongming Zhu \\ NASA Glenn Research Center, Cleveland, OH 44131, USA \\ Correspondence should be addressed to Maria A. Kuczmarski, maria.a.kuczmarski@nasa.gov \\ Received 25 November 2010; Revised 4 February 2011; Accepted 18 February 2011 \\ Academic Editor: Guan Yeoh
}

Copyright () 2011 Maria A. Kuczmarski et al. This is an open access article distributed under the Creative Commons Attribution License, which permits unrestricted use, distribution, and reproduction in any medium, provided the original work is properly cited.

\begin{abstract}
Burner rigs are routinely used to qualify materials for gas turbine applications. The most useful rig tests are those that can replicate, often in an accelerated manner, the degradation that materials experience in the engine. Computational fluid dynamics (CFD) can be used to accelerate the successful development and continuous improvement of combustion burner rigs for meaningful materials testing. Rig development is typically an iterative process of making incremental modifications to improve the rig performance for testing requirements. Application of CFD allows many of these iterations to be done computationally before hardware is built or modified, reducing overall testing costs and time, and it can provide an improved understanding of how these rigs operate. This paper describes the use of CFD to develop burner test rigs for studying erosion and large-particle damage of thermal barrier coatings (TBCs) used to protect turbine blades from high heat fluxes in combustion engines. The steps used in this studydetermining the questions that need to be answered regarding the test rig performance, developing and validating the model, and using it to predict rig performance—can be applied to the efficient development of other test rigs.
\end{abstract}

\section{Introduction}

A thermal barrier coating (TBC) is a layer of thermally insulating ceramic applied over an oxidation-resistant bond coat on a metallic component. TBCs protect a component from high, prolonged cyclic heat loads and extend part life by reducing thermal fatigue and reducing oxidation through reducing the component temperature. When used in turbine engines, these coatings may reduce the cooling airflow needed through and over components and allow significantly higher gas operating temperatures, leading to improved engine performance, greater fuel efficiency, and reduced carbon dioxide emissions [1-4].

Thermal barrier coatings are used to coat components such as combustor liners and turbine blades. The first row of turbine blades in the high-pressure turbine region encounters especially high-temperature, high-pressure, and high-velocity gases. These "first blade" TBCs are particularly prone to damage by erosion and large-particle impact $[5,6]$. When TBCs erode, the loss of insulation can lead to turbine blade damage from high heat exposure and may require additional cooling air to be directed to the leading edge of the blades to compensate, leading to lower operating efficiency for the engine.

TBCs have been used in the turbine engines of fixed-wing aircraft for some time, but are just beginning to be used in rotary-wing aircraft turbine engines. Fixed-wing commercial aircraft most often operate in relatively clean environments, such as high altitudes and on dedicated take-off and landing sites-runways maintained to keep them relatively free of dust and debris. Rotary-wing aircraft operates in much dirtier environments: lower altitudes and take-off and landing in a wide variety of locations, including environments with high dust concentrations. Rotary-wing aircraft turbine engines often use particle separators to decrease the number of particles that reach the engine. Although these separators are more effective for larger particles, some debris can still reach the turbine blades, particularly under heavy loading conditions [7]. Therefore, erosion and impact damage of TBCs on the first blade of rotary turbine engines is of particular concern [6]. 


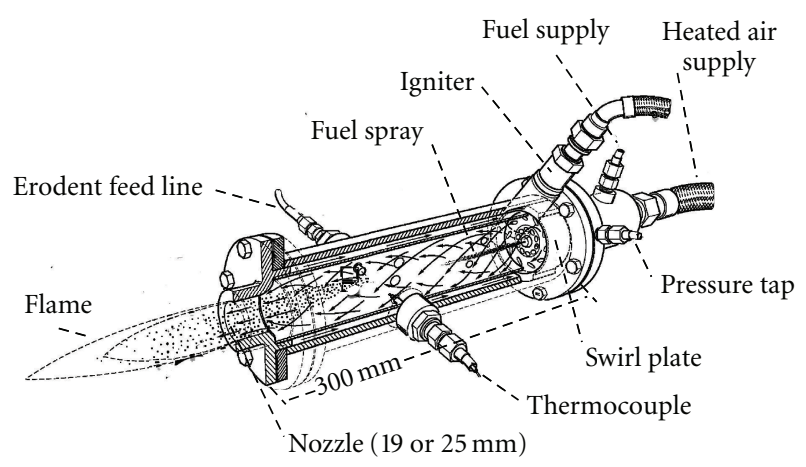

FIGURE 1: Schematic of an unducted burner-erosion rig.

Besides impact damage from large particles that enter from the outside environment, turbine blades may be struck by debris from within the engine, including pieces of TBCs that spall off the combustor walls [6]. In addition, old injectors that become damaged or clogged with dirt can spray fuel onto the combustor walls and deposit carbon. These deposits can break off in large "carbon balls" that can strike the turbine blades $[8,9]$. Fine particles such as dust are a particular problem for rotary-wing aircraft because of their operating environments. In addition to erosion, small particles may, under certain conditions, melt and lead to corrosive attack of the TBC. A discussion of this failure mechanism is beyond the scope of this paper.

Burner rigs are torches that burn jet fuel and preheated air. They are generally used to evaluate, rank, and understand the behavior of high-temperature materials for gas turbine applications. With burner rigs, gas and preheated air are mixed within the burner, and the combustion products exit through a nozzle to accelerate the gases to Mach 0.3 or higher subsonic velocities. This is illustrated in the schematic in Figure 1. Development of new rigs to study erosion and large-particle impact damage was undertaken at the NASA Glenn Research Center with the goal of developing more erosion-resistant turbine engine thermal barrier coatings. This work was built on and guided by two previous burner erosion rigs: a rig that existed at NASA in the 1980s as described by Handschuh [10] and a rig at GE described by Bruce [11].

The burner rig described by Handschuh consisted of a jet fuel combustor modified to inject erosive aluminum oxide particles with an average diameter of 130 microns into the centerline of the combustor. Burning fuel in the combustor provided gas at high temperature and high velocity. The test rig had a converging nozzle and, because he wished to maintain a narrow stream of erodent particles, sonic velocity was used to provide the greatest particle acceleration possible while minimizing the dispersion of aluminum oxide as it traveled downstream toward the test specimen. Evidence of particle diffusion was seen at the test specimen surface, which increased with the test specimen distance from the nozzle exit. The center of this diffusive pattern was not along the centerline of the combustor, even though particles were introduced at that location. An alternative design was mentioned that used a long vertical acceleration duct to allow the gas and particle velocities to become essentially the same. However, this design, while believed to be useful for studying the effect of particle velocity on the erosion process, was not implemented because it was thought that it would result in too much heat loss to the duct to produce high-temperature test conditions.

The burner rig described by Bruce consists of a combustor fed with jet fuel and compressed air that was modified to radially inject crushed alumina particles 50 and 560 micron in average diameter into the combustor in two horizontally opposite positions. Other erodent materials were considered, but alumina was selected because it produced damage patterns consistent with that observed in engines. The test specimens were cylindrical pins mounted on a carousel that rotated at $500 \mathrm{rpm}, 50 \mathrm{~mm}$ from the burner rig exhaust. It was concluded that particle velocity is affected by the particle size and distance from the combustor opening, but negligibly affected by air pressure, air temperature, and fuel flow rate. CFD was used with a trajectory code to determine an inviscid 2D flow field in which the trajectory of spherical particles was calculated. The results of this model produced good agreement with available experimental measurements of particle velocities at 50 and $100 \mathrm{~mm}$ from the combustor exhaust, and it was used to predict velocities for other distances from the exhaust and other particle materials. Bruce indicates that excessively high flow rates could lead to particles bouncing off the test specimen surface interfering with incoming particles, leading to reduced wear rate.

The most useful test results come from rigs that can replicate turbine engine failure modes. To understand if the modifications to the current NASA burner rigs would make them suitable for erosion and large-particle impact damage studies, three questions needed to be answered: (1) would the particles come to the gas temperature in the burnererosion rig? (2) would the particles move fast enough to accurately cause damage to the TBC surface? (3) how could the eroded region be broadened for cases where that would be advantageous, such as for more representative testing of small turbine blades? Rather than making best guesses as to whether the test rigs would meet these requirements, a CFD model was used to answer these questions.

This paper describes the CFD modeling used to guide modifications to previously existing NASA Glenn burner rigs through addition of an unattached duct to make them suitable for evaluating erosion and large-particle impact damage of TBCs for turbine engine applications and describes validation of the model to confirm that its predictions are accurate.

\section{Experimental Design}

Two separate burner rigs were to be modified: one for erosion studies and one for large-particle impact damage studies. Figure 2 shows a photograph of one of the burner-erosion rigs without a duct. The rigs are fired on a mixture of jet fuel and preheated air. Erodent particles are transported to the burner using a powder feeder of the type used for plasma 


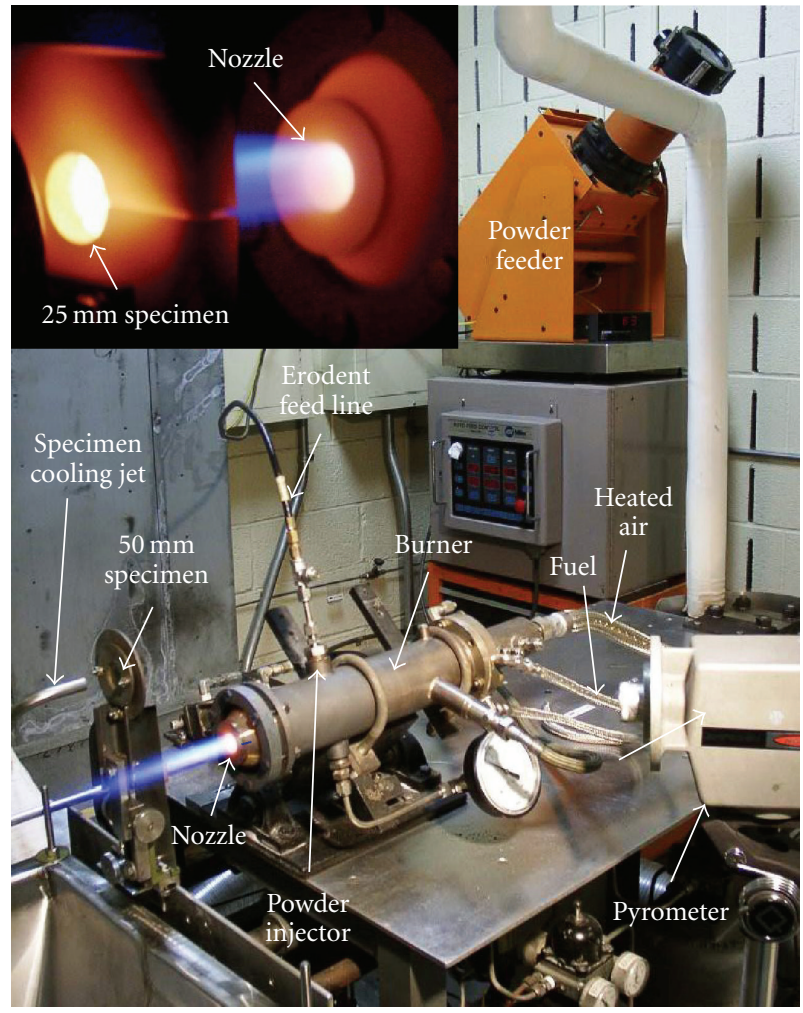

FIgURE 2: Photograph of an unducted burner-erosion rig during operation.

spraying introduced into the burner through a probe. The figures show that the particles come from the feeder, pass through the erodent feeding line, and are fed into the rig. The specimen and holder are shown in an idle position (not aimed at the specimen) in Figure 2; the burner pivots to move the flame into the path of the specimen for testing. Temperatures are generally measured using optical pyrometers, although thermocouples are an option. A unique feature of the NASA Glenn burner rigs is that they are routinely used for both ranking and fundamental studies of erosion of TBCs on turbine blades to guide development of erosion-resistant coatings.

Operating conditions were chosen to allow comparison to previous studies and to replicate TBC erosion in turbine engines. The particles used in this study had the physical properties of alumina. Initial CFD studies concentrated on single-particle sizes. For erosion studies, 26 micron and 50 micron diameter particle studies were conducted, since small particles were expected to be of particular concern in typical rotorcraft operating environments [12]. Nominal 26 micron diameter alumina particles are commercially available and can be reliably fed using plasma spray-type feeders of the type used for these experiments. 50 micron diameter particles were chosen to match the size used by General Electric in its studies of TBC erosion [11]. For large-particle impact damage studies, 560 micron diameter particles were chosen to match General Electric studies [11] and correspond to particle sizes that may originate from the combustor and are likely to cause impact damage [11]. Since real-world environments would contain a range of particle sizes, later studies used a particle size distribution centered about either 26 microns for erosion studies or 550 microns for large-particle impact damage studies. Mach numbers of 0.3-1.0 with gas temperatures up to $1640 \mathrm{~K}$ were chosen to represent conditions likely to be encountered by the gases interacting with the turbine blades.

\section{Model Description}

The computational fluid dynamics code ANSYS FLUENT (ANSYS FLUENT software from ANSYS, Inc., Canonsburg, Pa.) was used to model the experimental apparatus. The code uses a finite volume method to discretize the continuity, momentum, and energy equations. A steady state, compressible flow, axisymmetric model was used; various regions, dimensions, and boundary conditions are shown on Figure 3(a) for the unducted model and Figure 3(b) for the model with an unattached duct. This duct is at a distance of $0.127 \mathrm{~m}$ from the nozzle exit. This figure shows a duct that is $0.305 \mathrm{~m}$ long with a diameter of $0.019 \mathrm{~m}$ (drawn as $0.095 \mathrm{~m}$ radius). The diameter and length of the duct shown in this figure were varied during the study. The figures show a portion of the burner liner, the nozzle, and a box showing pressure boundaries (in blue). Because this is an axisymmetric model, this figure may be rotated about the axis of rotational symmetry to form the axisymmetric figure. Note that the entire length of the burner, 


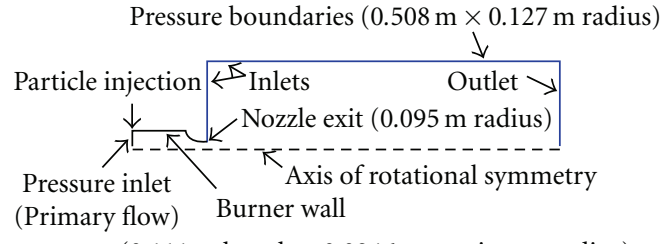

( $0.111 \mathrm{~m}$ length $\times 0.0246 \mathrm{~m}$ maximum radius $)$

(a)

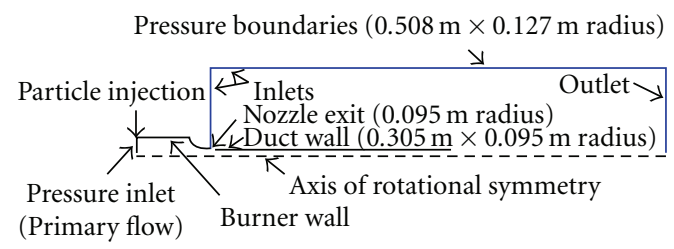

$(0.111 \mathrm{~m}$ length $\times 0.0246 \mathrm{~m}$ maximum radius $)$

(b)

FIgURE 3: Diagram with dimensions and boundary conditions for (a) unducted burner-erosion rig; (b) a ducted burner-erosion rig.

before the injection region, was not modeled. Rather the region just before particle injection was treated as a pressure inlet.

A standard $k-\varepsilon$ turbulence model was used with the C1epsilon constant altered from the standard value of 1.44 to 1.56 because of the successful use of this turbulence model by Senesh and Babu to describe the potential core and other characteristics of similar jets [13]. Strictly speaking, the $k$ $\varepsilon$ model is only applicable for fully developed turbulent flow [14]. For turbulent flow in pipes, the entrance length for fully developed flow is given by [15]:

$$
\frac{l_{e}}{D}=4.4 \operatorname{Re}_{D^{1 / 6}}
$$

where $l_{e}$ is the entrance length $(\mathrm{m}), D$ is the pipe diameter $(\mathrm{m})$, and $\operatorname{Re}_{D}$ is the Reynolds number based on pipe diameter (dimensionless).

The range of flows used in this study yielded Mach numbers at the nozzle exit from 0.3 to 1.0 , with Reynolds numbers of about 17,000 and 51,000, respectively. Entrance lengths were found to be between about 0.42 to $0.51 \mathrm{~m}$ for the $0.01905 \mathrm{~m}$ diameter duct and between 0.58 and $0.74 \mathrm{~m}$ for the $0.0254 \mathrm{~m}$ diameter duct. Since the location of the specimen was at $0.3683 \mathrm{~m}$, fully developed turbulent flow would not yet have been established by the time the flow reached the test specimen surface. Nonetheless, because the model with the modified $\mathrm{C} 1$ constant predicted a potential core having a length matching that observed experimentally-both in our case and with the work of Senesh and Babu [13] —it was felt that the $k-\varepsilon$ model would be fully adequate for the needs of this paper. Standard wall functions and viscous heating were both used in the model.

The discrete phase model was activated to allow solid particles to be injected into the gas flow and their paths tracked. These particles were allowed to interact with the gas phase.
A spherical particle drag law from Morsi and Alexander was used [16]

$$
C_{d}=a_{1}+\frac{a_{2}}{\operatorname{Re}}+\frac{a_{3}}{(\operatorname{Re})^{2}}
$$

where the values of the empirical constants $a_{1}, a_{2}$, and $a_{3}$ are described in Morsi and Alexander, and Re is the Reynolds number. This drag law was further modified for relative Mach numbers greater than 0.4 using a high Mach number drag law. ANSYS FLUENT computes the spherical particle drag coefficient in this range by using a look-up table that is a function of Reynolds number; this table is derived from published literature [17].

Injections were defined as inert particles released across the surface of the particle inlet. As mentioned previously, single-particle sizes of 26 and 50 micron diameter were used for erosion studies, and 560 micron diameter particles were used for large-particle impact damage studies. In the real world, a wide variety of particle sizes would impact the turbine blades in an engine. However, for the purposes of initial study, a simplified particle distribution containing three different sizes was used: 20, 26, and 32 microns for the erosion studies, and 500, 550, and 600 microns for the largeparticle impact damage studies.

A second-order upwind scheme was used for both the momentum and energy equations, with an under-relaxation factor set to 0.3 for the momentum equation and 1 for the energy equation. The convergence criteria for the solutions were defined as scaled residuals below $1 \times 10^{-5}$ for the momentum equation, $1 \times 10^{-6}$ for the energy equation, and $1 \times 10^{-3}$ for both the turbulent kinetic energy and dissipation rate. Decreasing these values, two orders of magnitude did not result in a change in the model predictions.

The sensitivity of the results to the grid density was studied using three different grid densities based on the number of cells used across the nozzle. A nonuniform grid was used over parts of the model to minimize the total number of computational cells. The maximum aspect ratio for the cells was $5: 1$. Using 10 cells across the nozzle yielded 15,393 total cells in the computational domain, 15 cells across the nozzle yielded 34,251 total cells, and 20 cells across the nozzle yielded 61,257 total cells. Comparisons were made among the grids for both temperature and velocity magnitude at a number of points spanning the nozzle radius at a distance of 0.1016 meter from the nozzle exit. Comparisons of temperature among the grids at identical points yielded differences of generally less than $1 \%$, with the maximum difference being 3\%. Similar comparisons of velocity magnitude yielded differences generally less than $2 \%$, with the maximum difference being $6 \%$. This shows that grid with 15,393 total cells, which was used for the rest of this study, is sufficient to achieve grid-independent results. The average $y^{+}$values ranged from about 30 for the Mach 0.3 cases to about 96 for the Mach 1.0 cases, within recommended values for these types of studies [14].

Simple restitution coefficients were assumed for these studies. The velocity restitution coefficient, which is the ratio of the velocity of a particle after a wall strike to its 
velocity before a wall strike, was set to 0.5 for all collision angles. This is essentially consistent with values reported in the literature for small particles at room temperature $[18,19]$. Note that a lack of angular dependence may imply a balanced combination of the effects of friction (whose effect is strongest at lower angles) and plastic deformation (whose effect is strongest at higher angles). Friction is related to surface roughness and particle size. Plasticity may be related to the hardness of the particle and the surface with which it collides.

For the case of large particles striking hard surfaces at room temperature, the restitution coefficient was measured to be near one (near elastic) for low-angle collisions falling to about 0.25 for high-angle collisions [18]. However, the duct is assumed to be mullite for the cases described in this paper, and mullite is soft at high temperature. The influence of hard versus soft substrates may be envisioned as a golf ball skipping on concrete versus skipping on partially dried mud. The near-elastic restitution coefficient measured for hard substrates at room temperature may not apply for mullite ducts. Therefore, even for the case of large particles, the directional restitution coefficient was set to 0.5 for the purposes of this study. Studies using a piecewise polynomial in terms of angle to match the data from reference 18 are described elsewhere [20]. The directional restitution coefficient for all cases was simply set to 1.0 , making the angle of reflection equal to the angle of incidence.

The trajectory of a discrete phase particle in ANSYS FLUENT is predicted by integrating the force balance on the particle in a Lagrangian reference frame. The force balance equates the particle inertia with forces acting on the particle. For initial design-concept studies, following the most probable path of the injected particles allowed better visualization of particle trajectories within the rigs. Steady state trajectory simulations were performed. The integration time step is determined from [14]

$$
\Delta t=\frac{\Delta t^{*}}{\lambda}
$$

where $\Delta t$ is the integration time step (s), $\Delta t^{*}$ is the estimated transit time for particle across computational cell (s), and $\lambda$ is the step length factor (dimensionless).

The maximum number of time steps was set to 5000, resulting in completion of the trajectory calculations through the entire model domain. A step length factor of 5 was used. It can be seen from this equation that in highvelocity areas, the particle will move more quickly through a computational cell, and the integration time step will be larger. In relatively low-velocity areas, the integration time step will be correspondingly slower. Maximum particle time steps for these studies ranged from about $6.75 \times 10^{-5}$ second for the 26 micron particles to $4.5 \times 10^{-4}$ second for the 550 micron particles. ANSYS FLUENT uses a mean fluid phase velocity in the trajectory calculations when the flow is turbulent, unless a stochastic tracking approach is used; in this case, the instantaneous fluid phase velocity replaces the mean fluid phase velocity. A random walk model was used when stochastic tracking was performed to predict

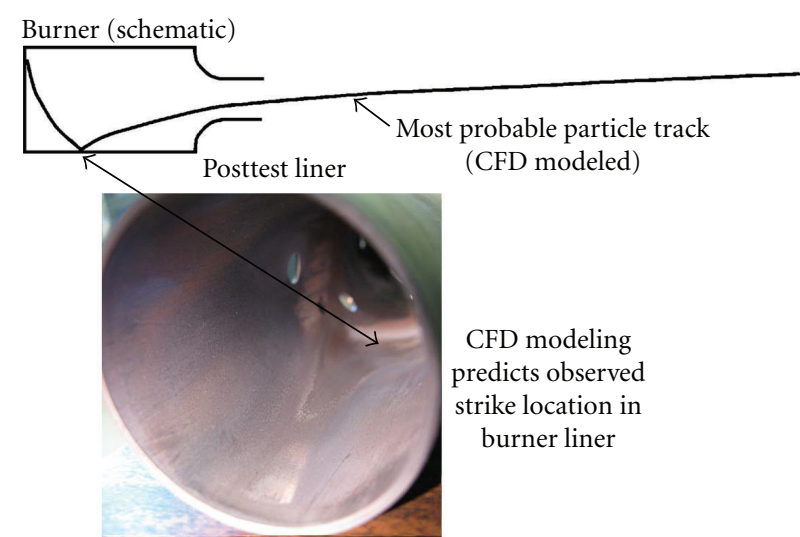

Figure 4: Model predictions of most probable location of particle strikes on wall correspond with eroded region seen in actual rig. Location of particle strikes/eroded region is about $0.05 \mathrm{~m}$ from the end of the liner/beginning of the nozzle.

the dispersion of particles due to turbulence [14]. Twenty stochastic tries with a time-scale constant of 0.15 were used. This last factor is related to the time spent in turbulent motion along the particle path [14].

\section{Model Validation}

An important part of any modeling work is determining if the model predictions can be trusted. This is done by comparing the model predictions to experimental observations, experimental measurements, and/or analytical expressions, if available. An experimental observation provided the first evidence that the model was accurately predicting what was happening in the test rigs. The model predicted the most probable particle trajectories through the burnererosion rig, showing where they would strike and bounce off an interior wall. Figure 4 is a simplified diagram showing the most probable path of one particle, along with a picture of a slightly eroded spot on the interior wall of the burner-erosion rig that corresponds to the predicted location of particle strikes-about $0.05 \mathrm{~m}$ ( 2 inches) from the nozzle exit. A large number of particles would actually be striking this location and locations around it due to effects such as the particle size distribution and turbulent dispersion. While the most probable trajectory is fully sufficient for our present requirements, future models employing statistical approaches and 3D models geometries are planned.

Model predictions agreed well with experimental temperature measurements. Figure 5 shows a plot of thermocouple measurements of the flame temperature at various positions along the centerline and CFD model prediction where an inlet temperature to the model domain of $1640 \mathrm{~K}$ was assumed. Inserts show an optical photograph and an infrared image of the hot central region of the burnererosion rig flame. This figure illustrates that the gases exiting the nozzle display a hotter region known as the potential 


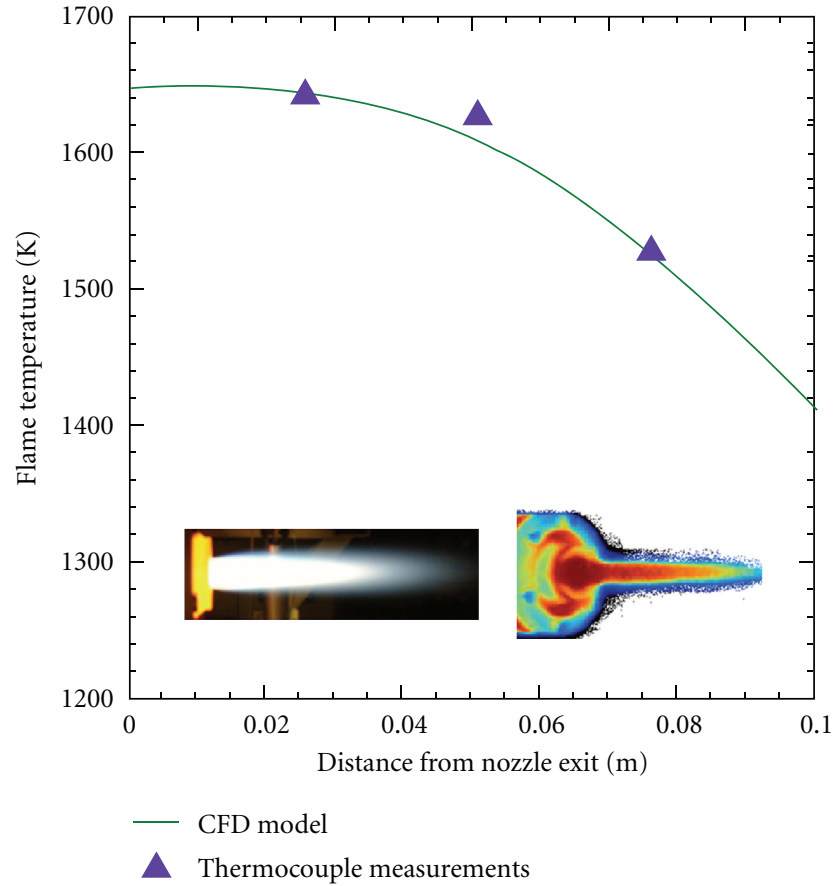

FIGURE 5: Measured and predicted temperatures versus distance from nozzle exit. Inserts show an optical photograph and an infrared image of the hot central region of the burner-erosion rig flame.

core, and that the CFD model correctly predicts the temperature distribution within the potential core. Good agreement between the two is another indication that the model is accurately predicting the burner-erosion rig performance.

Figure 6(a) shows a comparison at the same locations and for the same inlet Mach number between model predictions and experimental measurements taken using a Canon 50D digital camera. The camera is capable of sufficiently high resolution (15 megapixel), fast shutter speed $(1 / 8000 \mathrm{~s})$, and high speed $(12,800 \mathrm{ISO})$ that it can, with the right combination of lenses, be used as a streak camera to determine the velocities of the hot, glowing particles. At an inlet Mach number of 0.5 , the model predicts a particle velocity of $160 \mathrm{~m} / \mathrm{s}$ at $0.025 \mathrm{~m}$ (1 inch) from the nozzle outlet along the centerline; experimental streak photography measurements using the camera employing a telephoto-lensplus-close-up lens combination observed particle velocities of about $165 \mathrm{~m} / \mathrm{s}$, as shown in Figure 6(b). This excellent agreement is another indication that the model successfully predicts the burner-erosion rig performance.

The model successfully explained the experimentally observed location of the eroded pattern on the test specimen, which was mostly below the centerline. Figure $7(a)$, a diagram of the most probable particle trajectories from the model for the case of a $0.305 \mathrm{~m}$ duct, shows that the smallest diameter particle modeled was predicted to have a trajectory that carried it to the lower half of the test specimen. The largest diameter particle reflected off the walls in such a way as to cause it to also strike the lower half of the test specimen. The particle moving closest to the centerline

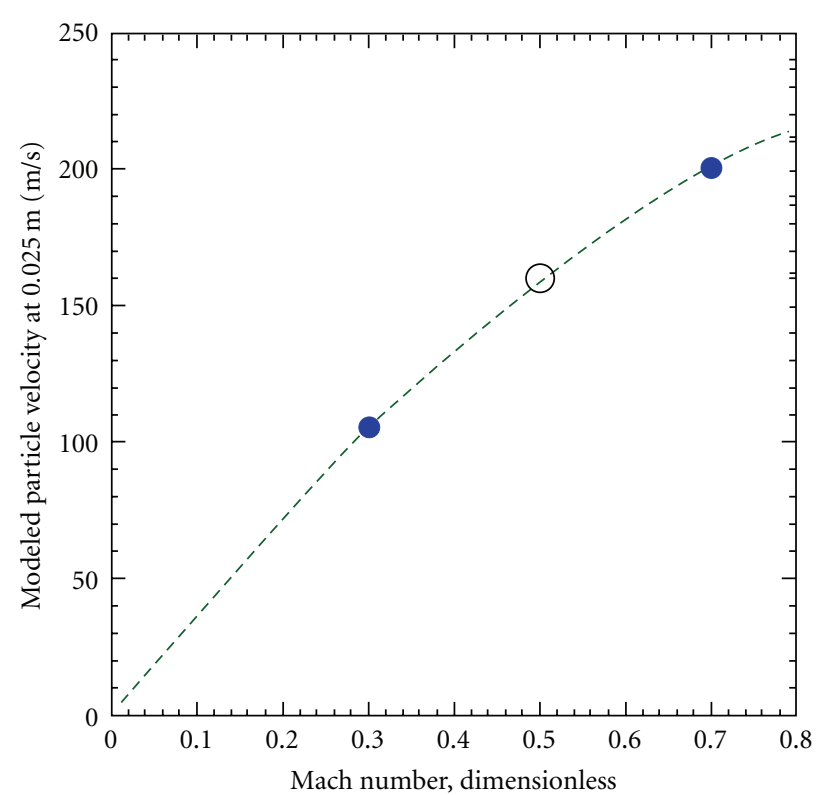

(a)

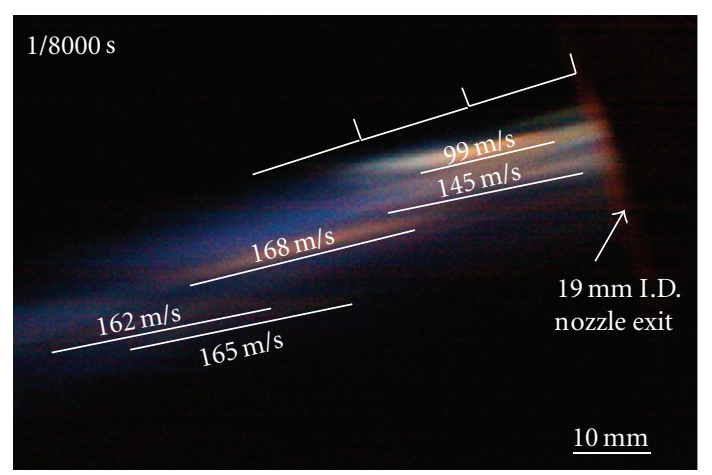

(b)

Figure 6: (a) Predicted particle velocities; (b) experimental measurements of particle velocity using a high-speed camera. Lines are drawn over particle traces for clarity.

strikes near the center of the test specimen.Figure 7(b) shows that the eroded region of the test specimen is mainly at and below the centerline, corresponding to the particle paths in Figure 7(a). Such agreement between model predictions and experimental observations provides further confidence in the model.

Two effects that would broaden the predicted particle track locations at the specimen would be inclusion of a large number of particles each having different diameters and inclusion of turbulent dispersion. In order to make an initial assessment of how dispersion may affect particle trajectories, and to examine this independent of particle size, one of the tracks from Figure 7(a) was re-examined, but with stochastic tracking applied. The 20 micron particle injected at $20 \mathrm{~m} / \mathrm{s}$ was selected because the most probable path for this particle is predicted to remain above the centerline before exiting the burner and below the centerline after exiting the duct. This makes it easier to interpret the axisymmetric results in 


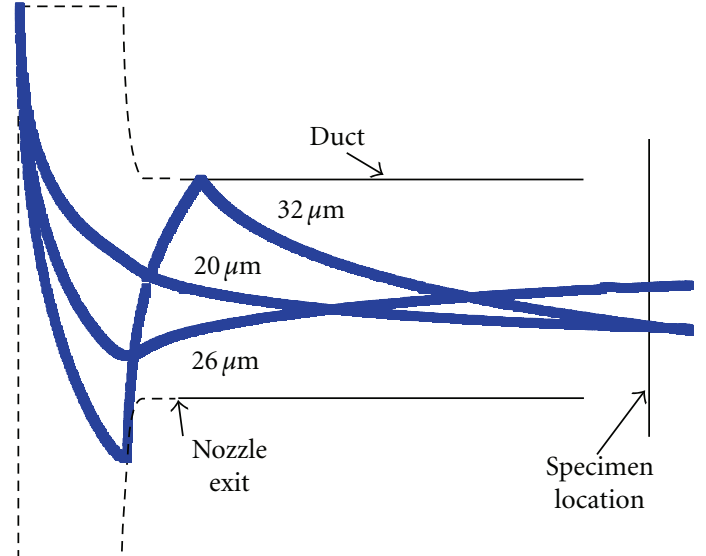

(a)

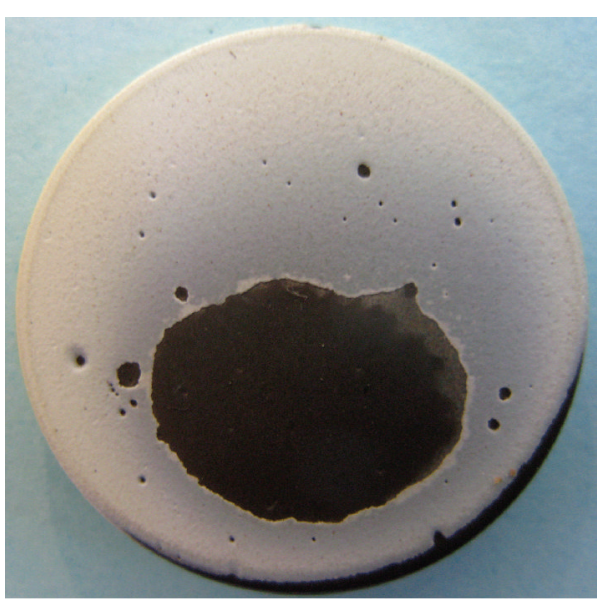

(b)

Figure 7: (a) Diagram of trajectories of three particles with different diameters in a Mach 0.5 ducted burner rig ( $0.305 \mathrm{~m}$ long duct); (b) experimental observation of eroded pattern on test sample. Model predictions correspond to experimental observations that most particle strikes occur below the centerline.

terms of which radial half the particle is actually travelling in. Figure 8 represents the results of this calculation. It shows the region of the burner and the region after the duct exit. In this figure, the particles are colored by velocity, with blue representing velocities as low as $20 \mathrm{~m} / \mathrm{s}$ and red representing velocities as high as $294 \mathrm{~m} / \mathrm{s}$. The figure shows that within the burner, the particles do not deviate far from the most probable path. However, after the particles travel through the $0.305 \mathrm{~m}$ duct, the effect is to broaden the distribution of particle tracks considerably, filling up much the lower half of the duct. Significantly, those tracks traveling near the center of the duct are traveling at higher velocities. Since damage to the coated specimen is expected to be proportional to particle velocity raised to a power that initial studies suggest may be 3 [21], the amount of damage would be expected to be biased towards the higher velocity center of the duct exit. Furthermore, it may be useful to try to experimentally determine the injection velocity that causes the majority of the particles to exit near the center of the duct. Future investigation of the effect of dispersion will benefit from future 3D models where particle tracks may be unambiguously visualized.

Figure 9 shows model predictions for particle velocity for the $0.305 \mathrm{~m}$ duct case as a function of distance from the nozzle for three different particle diameters compared to particle velocities obtained from an analytical expression that assumes a uniform gas stream. It is based on an existing expression [22] that was rederived for the case of nonzero initial velocity and combined with a drag law that covered the range of Reynolds numbers used in this study [23]. This equation is given by

$$
\begin{aligned}
& x_{f}-x_{i}= \\
& \frac{4}{3} D \frac{\rho_{p}}{\rho} \int_{V_{i}}^{V} \frac{V_{p} d V_{p}}{0.2924\left[1+\left(9.06 /(\mathrm{Re})^{0.5}\right)\right]^{2}\left(V-V_{p}\right)\left|V-V_{p}\right|} .
\end{aligned}
$$

The plots of the CFD modeled and analytically modeled velocities agree very well with each other. The exception is the case where the largest diameter particle strikes the duct wall. The CFD model predicts that the velocity drops by a factor of two after the wall strike based on the assumed restitution coefficient of 0.5 . The analytical model cannot account for the wall strike. However, it is interesting that the analytical modeling shows that much of the velocity lost after the wall strike is recovered after the particle travels further down the duct. The analytical curves in the figure were obtained using numerical integration due to the complexity of accurate drag law equations. The excellent agreement between the model predictions and the results of the analytical expression further validates the model.

\section{Results}

Initial computational runs focused on the nonducted burner-erosion rig. The particle temperature influences its hardness and, therefore, the damage it causes upon striking the specimen. Figure 10(a) shows the modeled heating of a 26 micron and a 550 micron particle in a ducted burner rig operated at Mach 0.5 , as well as both the static and stagnation gas temperatures. The duct was $0.305 \mathrm{~m}$ long, with a diameter of $0.01905 \mathrm{~m}$. The $x$-axis represents the radial distance from the nozzle exit of the burner rig. The 26 micron particle reaches the static temperature of the gas within the duct and then drops in temperature in line with the drop in the gas static temperature. The 550 micron particle, which has nearly 10,000 times the mass of the 26 micron particle, reaches a maximum temperature of about $600 \mathrm{~K}$. The fact that the small particles come to high temperature is consistent with the streak-camera velocity measurements shown in Figure 6(a), where the particles are observed to glow. The large particles would not be glowing except possibly by reflection. Camera-based velocity measurements for the large particles may require the use of an external light source, such as a strobe. The lower temperature large particles may be harder (especially for certain erodents with strongly temperature-dependent properties) and, therefore, more 


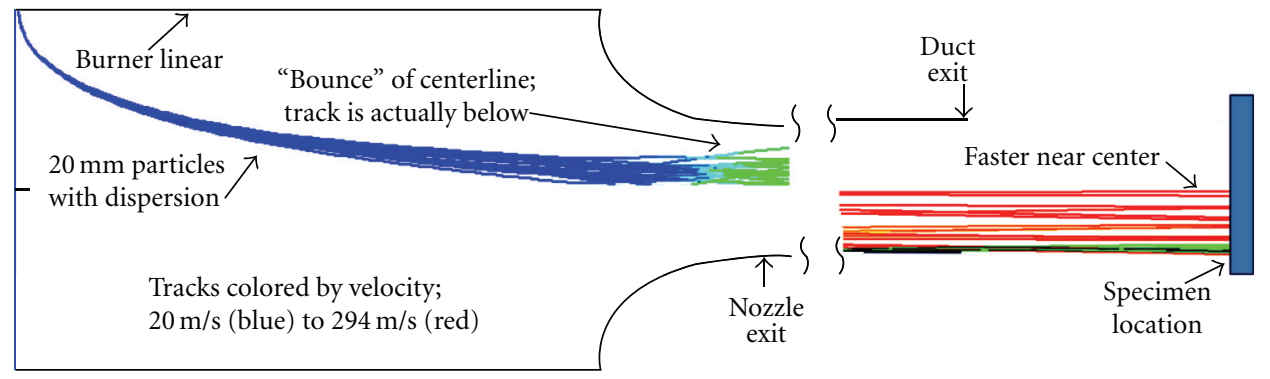

FIGURE 8: Diagram of trajectories of 20 micron particles in a Mach 0.5 ducted burner rig with turbulent dispersion.

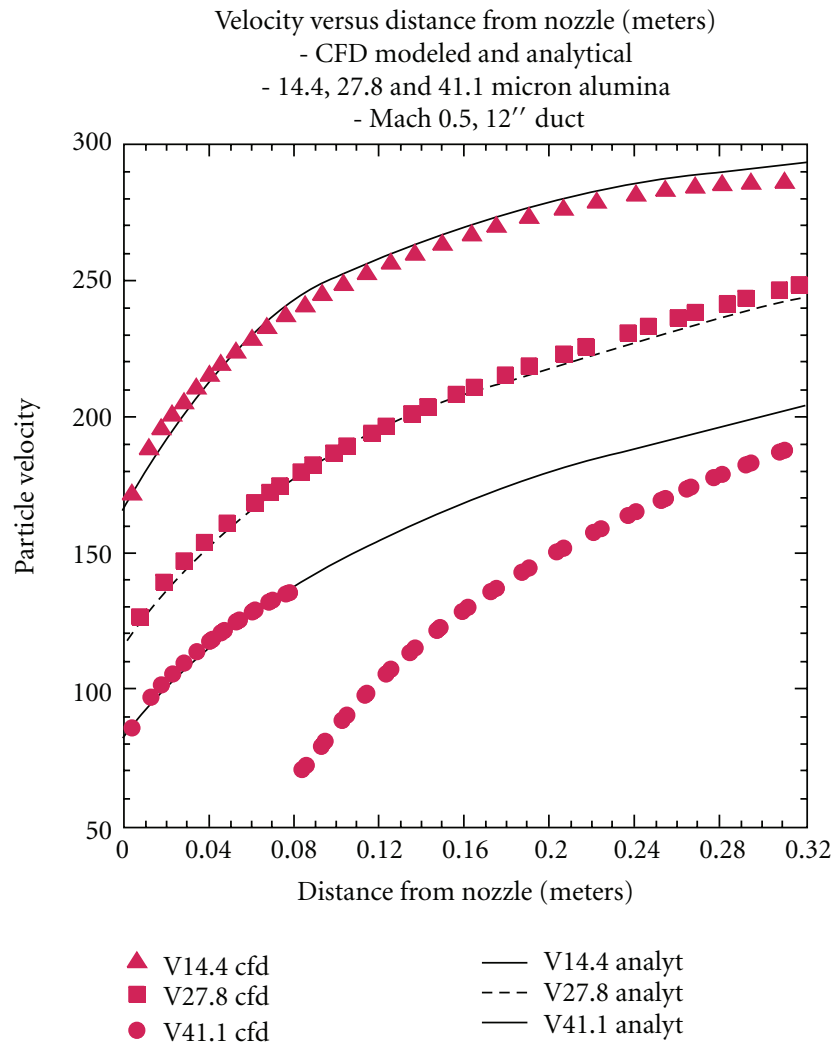

Figure 9: Comparison of particle velocity for particles with three different diameters obtained from model predictions with that obtained from an analytical expression of particle velocity with nonzero initial velocity in a Mach 0.5 burner rig $(0.305 \mathrm{~m}$ long duct).

aggressive in degrading the TBC than the high-temperature small particles.

In order to validate these results, an examination of the particle temperatures under these conditions was undertaken using both a lumped capacitance model and a sphere in cross-flow model. Figure 10(b) examines the early stages of heating within the burner where gas temperature and pressure are essentially constant. Since heating was arbitrarily selected to occur over a narrow temperature range (293 to $360 \mathrm{~K}$ ), the heat capacity and particle velocity do not vary greatly. Therefore, a lumped capacitance model can be used to determine heat transfer coefficient, $h$, from the gas to the spherical particle [24]. This model means that the particle heats up uniformly-there is no gradient between surface and interiors temperatures. The lumped capacitance model is valid for spheres when the Biot numbers are less than 0.1. The Biot number for spheres may be expressed as

$$
\mathrm{Bi}=\frac{h(D / 6)}{k}
$$

where $h$ is the heat transfer coefficient $\left(\mathrm{W} / \mathrm{m}^{2} \cdot \mathrm{K}\right), D$ is the particle diameter $(\mathrm{m})$, and $k$ is the thermal conductivity $(\mathrm{W} / \mathrm{m} \cdot \mathrm{K})$.

Biot numbers for the 26 and 550 micron particles were found to be 0.0018 and 0.0038 , respectively, well below the value of 0.1 necessary for the lumped capacitance model to apply.

According to the lumped capacitance model for heat transfer from a fluid to a sphere,

$$
\frac{\theta}{\theta_{i}}=\frac{\left(T-T_{\infty}\right)}{\left(T_{i}-T_{\infty}\right)}=\exp \left[\left(\frac{-6 h}{\rho D C_{p}}\right) \times t\right],
$$

where $T_{i}$ is the initial gas temperature $(\mathrm{K}), T_{\infty}$ is the free stream temperature $(K), T$ is the sphere temperature $(K), \rho$ is the sphere density $\left(\mathrm{kg} / \mathrm{m}^{3}\right), D$ is the sphere diameter $(\mathrm{m}), C_{p}$ is the sphere heat capacity $(\mathrm{J} / \mathrm{k} \cdot \mathrm{K})$, and $h$ is the heat transfer coefficient $\left(\mathrm{W} / \mathrm{m}^{2} \cdot \mathrm{K}\right)$.

Rearranging this equation yields

$$
\ln \left(\frac{\theta_{i}}{\theta}\right)=\left[\frac{6 h}{\rho D C_{p}}\right] t .
$$

This is a linear equation in which the slope is equal to $6 h / \rho D C_{p}$.

Using data obtained from the ANSYS FLUENT model for the initial particle temperature rise, a plot of $\ln \left(\theta_{i} / \theta\right)$ versus the particle residence time is produced for both 26 and 550 micron particles, and the slope of these curves was used to determine convective heat transfer coefficients of $12,500 \mathrm{~W} / \mathrm{m}^{2} \cdot \mathrm{K}$ for the 26 micron diameter particles and $1260 \mathrm{~W} / \mathrm{m}^{2} \cdot \mathrm{K}$ for the 550 micron diameter particles.

In order to validate these results, the heat transfer coefficient was calculated for a sphere in crossflow [24] and compared to those obtained from the lumped capacitance 


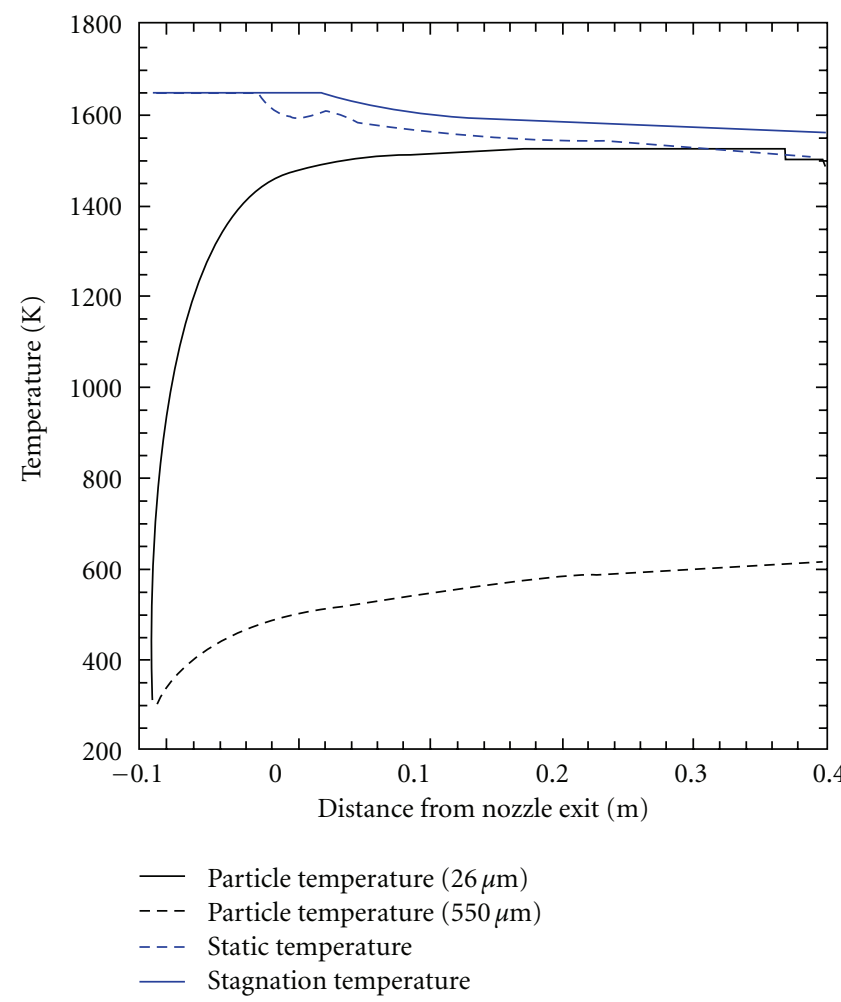

(a)

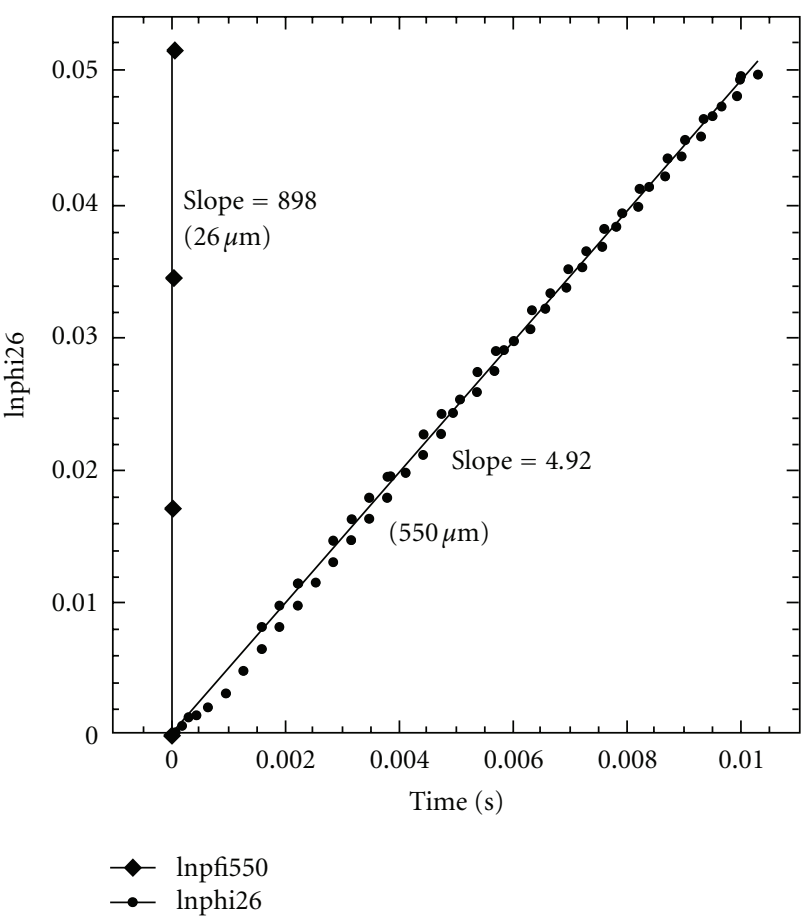

(b)

FIGURE 10: (a) Plot of particle temperatures for 26 and 550 micron diameter particles and gas static and stagnation temperature as a function of distance from the nozzle. (b) Plot of the logarithm of temperature ratio versus time for the early stages of particle heating for 26 and 550 micron particles.

model. A heat transfer correlation proposed by Whitaker gives a heat transfer correlation as [25]

$$
\overline{\mathrm{Nu}}_{D}=2+\left(0.4 \operatorname{Re}_{D}^{1 / 2}+0.06 \operatorname{Re}_{D}^{2 / 3}\right) \operatorname{Pr}^{0.4}\left(\frac{\mu}{\mu_{s}}\right)^{1 / 4},
$$

where $\mathrm{Nu}$ is the Nusselt number (dimensionless), Re is the Reynolds number (dimensionless), and Pr is the Prandtl number (dimensionless).

These dimensionless numbers are given by

$$
\begin{gathered}
N u=\frac{h D}{k}, \quad \operatorname{Re}=\frac{\rho \bar{u} D}{\mu}, \quad \operatorname{Pr}=\frac{v}{\alpha}, \\
v=\frac{\mu}{\rho}, \quad \alpha=\frac{k}{\rho C_{p}},
\end{gathered}
$$

where: $h$ is the heat transfer coefficient $\left(\mathrm{W} / \mathrm{m}^{2} \cdot \mathrm{K}\right), D$ is the spherical particle diameter $(\mathrm{m}), k$ is the thermal conductivity $(\mathrm{W} / \mathrm{m} \cdot \mathrm{K}), \rho$ is the density $\left(\mathrm{kg} / \mathrm{m}^{3}\right), \bar{u}$ is the mean fluid velocity $(\mathrm{m} / \mathrm{s}), \mu$ is the dynamic viscosity $(\mathrm{kg} / \mathrm{m} \cdot \mathrm{s}), \mu_{s}$ is the dynamic viscosity evaluated at the spherical particle temperature $(\mathrm{kg} / \mathrm{m} \cdot \mathrm{s}), v$ is the kinematic viscosity $\left(\mathrm{m}^{2} / \mathrm{s}\right)$, and $\alpha$ is the thermal diffusivity $\left(\mathrm{m}^{2} / \mathrm{s}\right)$.
Equation (7) is valid for:

$$
\begin{gathered}
0.71<\operatorname{Pr}<380, \\
3.5<\operatorname{Re}_{D}<7.6 \times 10^{+4}, \\
1.0<\left(\frac{\mu}{\mu_{s}}\right)<3.2 .
\end{gathered}
$$

$\mathrm{Re}_{D}$ represents the Reynolds number based on the particle diameter. The conditions for this study yielded a Prandtl number of 0.71 (a typical value for air whether at $1640 \mathrm{~K}$ or at room temperature). Reynolds numbers based on the particle diameter varied from 5.6 for the 26 micron particles to 116 for the 550 micron particles, and a ratio of dynamic viscosities of 2.94, making (8) valid for use in validating the CFD results in this study.

Properties were evaluated at the free stream gas temperature, $T_{\infty}$, except for $\mu_{s}$, which was evaluated at the temperature of the sphere. The calculations used a gas velocity of $48 \mathrm{~m} / \mathrm{s}$ plus a small correction for the particle injection velocities $(10 \mathrm{~m} / \mathrm{s}$ for the 26 micron particle, $3 \mathrm{~m} / \mathrm{s}$ for the 550 micron particle); since injections start out at right angles to the flow, the relative velocities between $48 \mathrm{~m} / \mathrm{s}$ and $3 \mathrm{~m} / \mathrm{s}$ or $10 \mathrm{~m} / \mathrm{s}$ were used. The Reynolds numbers were 5.6 for the 26 micron particles and 116 for the 550 micron particles. The pressure was $118550.25 \mathrm{~Pa}(1.17 \mathrm{~atm})$. Gas thermal conductivity and viscosities were obtained from data 
in Holman [26]. These calculations yielded heat transfer coefficients of $8660 \mathrm{~W} / \mathrm{m}^{2} \cdot \mathrm{K}$ for the 26 micron particles and $1060 \mathrm{~W} / \mathrm{m}^{2} \cdot \mathrm{K}$ for the 550 micron particles. Compared to the results from the lumped capacitance model, the calculated heat transfer coefficient is about $16 \%$ smaller for the 26 micron diameter particle and about 30\% smaller for the 550 micron particle. The sphere in crossflow estimates agrees in magnitude with the lumped capacitance values obtained using CFD-predicted values for particle temperatures, thereby further validating the model predictions.

Although there are no standards applying to burnererosion rigs, it is worth examining the ASTM G76-07 standard that applies to pressurized gas jet erosion testing, which recommends a minimum particle velocity of $30 \pm$ $2 \mathrm{~m} / \mathrm{s}$ for erosion studies [27]. In an actual turbine engine, particles would be moving much faster, the turbine blade would be moving at a high tip speed, and the temperatures would be high. For the purposes of this study, faster moving particles are generally preferred, unless erosion begins to occur too rapidly. This would be more likely for the largeparticle impact damage studies. Figure 11 shows the particle velocity as a function of distance from the injector for both 50 and 560 micron diameter particles at both Mach 0.4 and Mach 0.9 in the unducted rig. Except for the largest particles at the lowest Mach number, the model predicts that all the particles would come to at least the ASTM-recommended velocity by the time they reached the test specimen, with the lighter particles coming to a substantially higher velocity. Figure 12 shows the particle tracks for 27 micron diameter particles injected at three different injection velocities under Mach 0.5 conditions in the unducted rig. The highest particle velocity at the surface of a specimen located $0.076 \mathrm{~m} \mathrm{(3}$ inches) from the nozzle exit, and, therefore, the highest erosion rate occurs for particles that move roughly along the centerline of the test rig. Adjusting the particle injection velocity to move as many particles as possible along the centerline would maximize the erosion rate and place this maximum at the center of the test specimen.

The ASTM G76-07 standard calls for erosion regions that are relatively small in diameter; however, it may be desirable in certain cases to broaden the damaged region. For example, a wider erosion pattern may be more representative of exposure of small turbine blades in the engine. Tests using the experimental rig modeled for this paper found that moving the test specimen from $0.05 \mathrm{~m}$ to $0.15 \mathrm{~m}$ from the nozzle outlet broadened the eroded region. However, this also moves the test specimen to a cooler region of the flame and reduces the similarity to turbine engine temperature conditions. One way to maintain the temperature at the test specimen surface at $2000^{\circ} \mathrm{F}$ or above is to direct the hot gases and particles exiting from the nozzle into a duct. Modeling showed that when the duct diameter was equal to the nozzle diameter, the typical result was higher particle velocities with little loss of gas temperature. As mentioned earlier, cycling is accomplished in the NASA Glenn burner rigs by pivoting the rig, which can be an issue for the duct approach. Pivoting the rig would result in a misalignment or separation of the attached duct. A possible solution would be

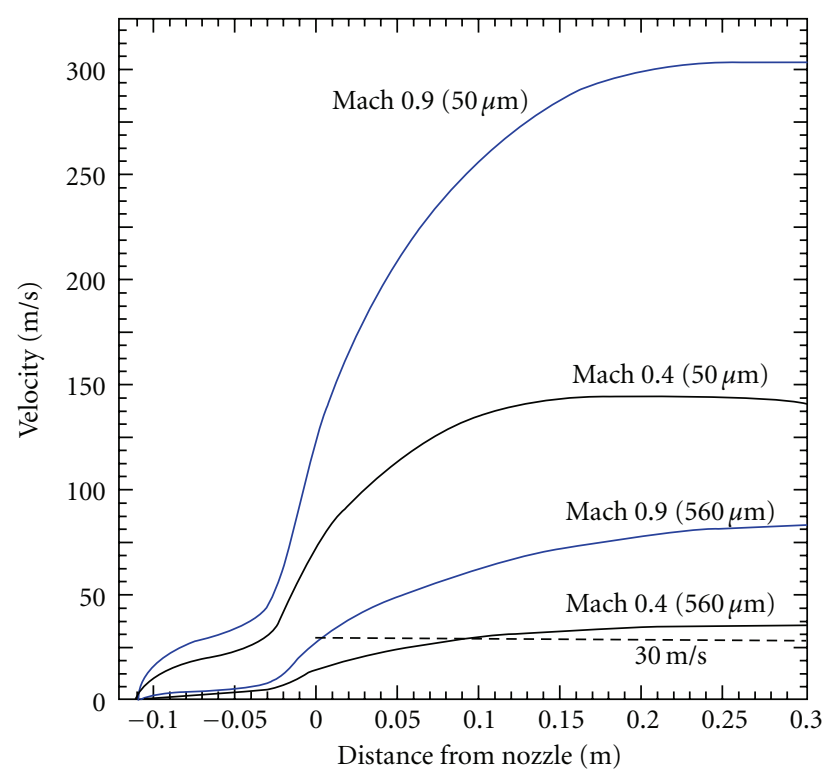

Figure 11: Particle velocity as a function of distance from the nozzle for Mach numbers of 0.4 and 0.9 , and particle diameters of 50 and 560 microns in an unducted burner rig. The minimum recommended particle velocity of $30 \mathrm{~m} / \mathrm{s}$ for erosion studies is shown by the dashed line.

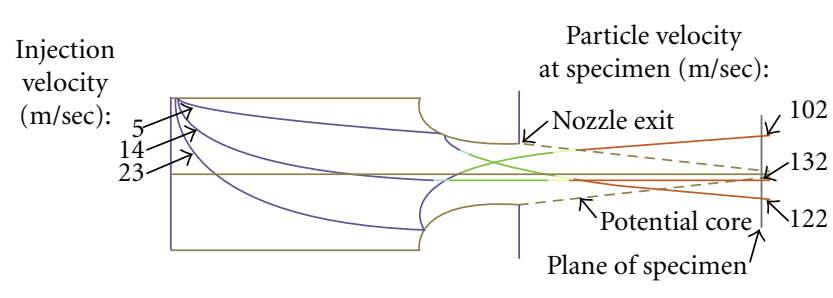

FIGURE 12: Most probable particle trajectories for various injection velocities in an unducted burner rig operated at a Mach number of 0.3 and a single-particle diameter of 26 microns. Note that interior bouncing can result in particles injected at higher velocities tracking toward the upper half of the test specimen, and particles injected at lower velocities can track toward the lower half of the test specimen.

to use an unattached duct, leaving a small distance between the nozzle exit and the duct. The model was used to examine the effects of ducts of different diameters and lengths on the gas temperature and velocity to determine if the rig performance would be adversely affected by an unattached duct.

Figure 13 shows the gas temperature and gas velocity as functions of distance from the nozzle exit for an unattached duct placed $0.0127 \mathrm{~m}$ from the nozzle outlet. As the duct diameter decreases, the gas temperature is maintained for a much longer distance. The gas velocity increases through the duct, which results in an increased particle velocity that is maintained farther down the duct as the particle diameter decreases. The smallest duct diameter in Figure 13 matches the diameter of the nozzle. The figure shows that high-gas temperature is maintained out to about $0.4 \mathrm{~m}$ for the duct having smallest diameter and the $0.305 \mathrm{~m}$ length. Therefore, 


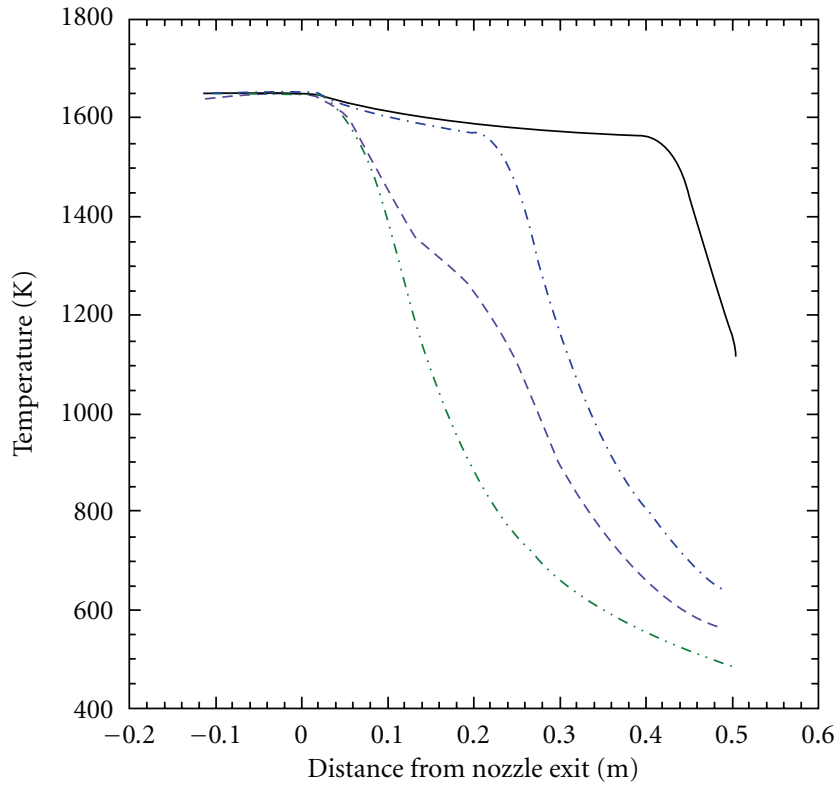

(a)

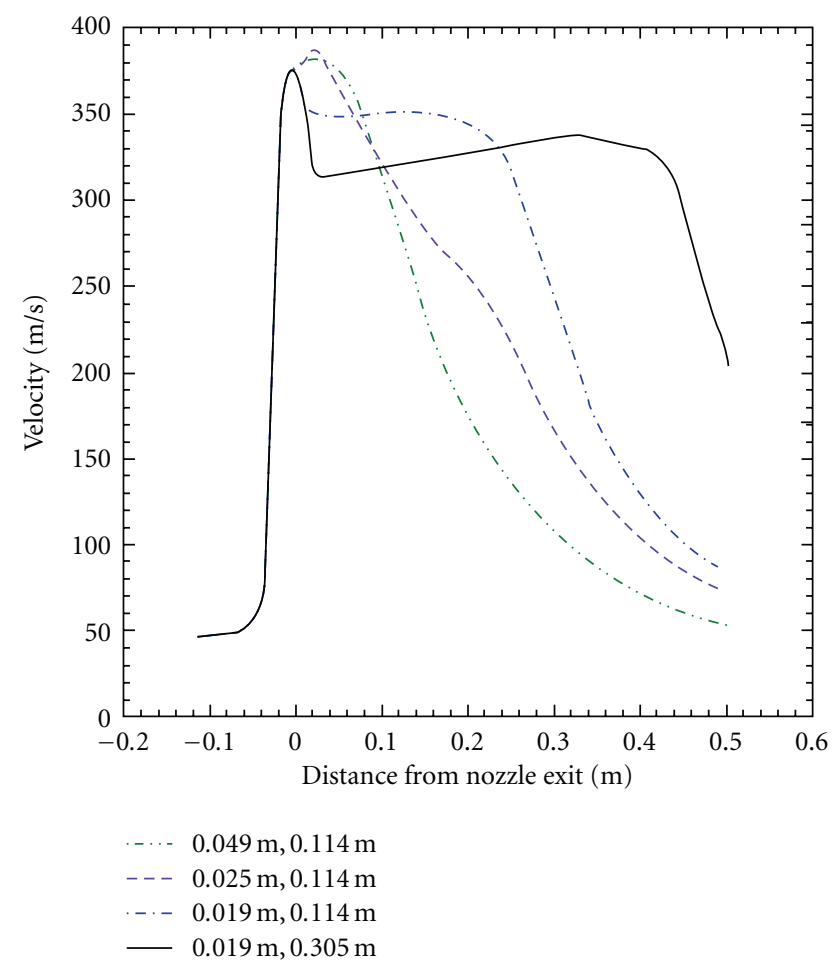

(b)

FIGURE 13: Plots as a function of distance from the nozzle exit of (a) gas temperature and (b) gas velocity for four different duct diameters (Mach 0.5 nozzle exit conditions).

the model predicts that an unattached ducted rig with the duct and nozzle of the same diameter of $0.01905 \mathrm{~m}$ gives the highest particle velocity, while still maintaining a high temperature at the test specimen surface.

Damage to the interior walls of the erosion and largeparticle impact damage test rigs was identified as a potential

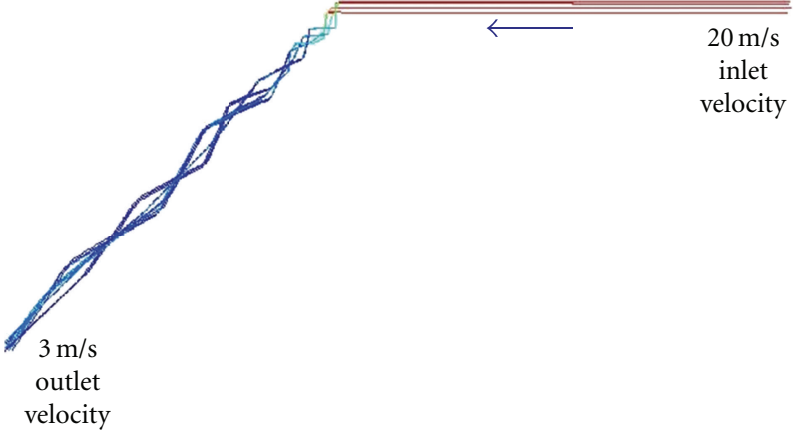

FIgURE 14: Particle tracks, with entrance and exit velocities, in 45 degree elbow. Outline of elbow is not shown in order to better show particle trajectories.

problem. This damage could be mitigated by reducing the particle velocities, but could result in failure to feed properly. Ideally, the particle velocities should be high enough to ensure that they are conveyed down the feed line, but low enough to avoid damage to the interior walls of the test rigs. A three-dimensional computational model of a 45 degree elbow was constructed to investigate whether particles leaving the feeder at a high velocity could be slowed before being injected into the test rigs. Since damage to the test rig walls would be most severe at the highest Mach numbers for the largest particle diameters, runs were conducted at Mach 0.7 for particles with a mean diameter of 550 microns. Model settings were the same as previously described for the test rigs. Figure 14 shows that the model predicts that particles injected at $20 \mathrm{~m} / \mathrm{s}$, a high enough velocity for conveying particles through a feed line, are slowed to about $3 \mathrm{~m} / \mathrm{s}$ at the injection point into the test rig. This velocity would greatly decrease damage to the interior test rig walls. As shown previously, use of the unattached duct will cause particles to accelerate to a sufficient velocity by the time they reach the test specimen.

\section{Conclusions}

This paper described the process used to guide the design of test rigs for both erosion and large-particle impact damage studies of TBCs for turbine engine blades. The model demonstrated that the three major conditions necessary for successful testing with these rigs would be met for the 26 micron diameter particles. The erodent particles come to nearly the gas temperature for the unducted rig and to the gas temperature for the ducted rig, replicating the temperature experienced by particles in a turbine engine. The erodent particles would move at a sufficiently high velocity to replicate damage to blade coatings observed in turbine engines. In the unducted rig, small particles reach well above the ASTM minimum recommended velocity for erosion testing. The particle velocity can be increased through the use of an unattached duct, with the highest sustained velocity occurring for the $0.035 \mathrm{~m}$ duct with a duct diameter equal to the nozzle diameter. The eroded region can be broadened by moving the test specimen farther 
from the nozzle and using an unattached duct to maintain particle temperature and increase particle velocity at the test specimen surface as long as the duct had the same diameter as the exit nozzle.

It was shown that the 550 micron particles could attain the ASTM minimum recommended velocity, and that the damage region on the test specimen could be broadened through the use of an unattached ducted rig with a diameter equal to the nozzle diameter. However, these larger particles did not come to the gas temperature. Fortunately, for the case of alumina erodent, this may not be a serious concern because the hardness of alumina does not change greatly with temperature. If other erodents were to be used, the effect of temperature on hardness may have to be considered. For the unattached duct case, the gas temperature and particle velocity are, as with the small particles, mostly maintained when the duct and the nozzle are of equal diameter. The fastest velocities and the highest erosion rates occur when the erodent particles exit as close to the centerline of the test rig as possible. The model demonstrated that potential damage to the interior walls of the test rigs caused by high inlet particle velocities could be mitigated through the use of a 45 degree elbow to slow the inlet particle velocities. These velocities would increase to test-velocity conditions as they are accelerated through the unattached duct.

Examples of excellent agreement of model predictions with experimental observations, experimental measurements, and an analytical expression of particle velocities demonstrate that this model can be used to predict the performance of the burner-erosion test rigs. This greatly decreased the development time for the rigs over trialand-error approaches and allows predictions of future rig performance if operating conditions are changed. This computational approach can be applied to the development of a variety of rigs for materials testing.

\section{Acknowledgment}

The authors gratefully acknowledge the support of this work by the NASA Fundamental Aeronautics program, Subsonic Rotary Wing project.

\section{References}

[1] D. Zhu and R. A. Miller, "Thermal-barrier coatings for advanced gas-turbine engines," MRS Bulletin, vol. 25, no. 7, pp. 43-47, 2000.

[2] F. O. Soechting, "Design perspective on thermal barrier coatings," Journal of Thermal Spray Technology, vol. 8, no. 4, pp. 505-511, 1999.

[3] N. P. Padture, M. Gell, and E. H. Jordan, "Thermal barrier coatings for gas-turbine engine applications," Science, vol. 296, no. 5566, pp. 280-284, 2002.

[4] R. A. Miller, "Ceramic thermal barrier coatings," Surface and Coatings Technology, vol. 30, no. 1, pp. 1-11, 1987.

[5] T. Strangman, D. Raybould, A. Jameel, and W. Baker, "Damage mechanisms, life prediction, and development of EB-PVD thermal barrier coatings for turbine airfoils," Surface and Coatings Technology, vol. 202, no. 4-7, pp. 658-664, 2007.
[6] A. Maricocchi, A. Bartz, and D. Wortman, "PVD TBC experience on GE aircraft engines," Journal of Thermal Spray Technology, vol. 6, no. 2, pp. 193-198, 1997.

[7] W. J. Tingle, W. R. Oliver, and K. Kirtley, Particle Separator Using Boundary Layer Control, General Electric Company, 2010.

[8] T. E. Strangman, D. Narasimhan, J. P. Armstrong, and K. R. Karasek, Carbon Deposit Inhibiting Thermal Barrier Coating for Combustors, Honeywell International, Inc., New York, NY, USA, 2001.

[9] T. E. Kuhn, W. G. Freeman, F. S. Maszk, D. P. Freiberg, K. A. Struzek, and L. A. Kobold, Apparatus and Method for Controlling Combustor Liner Carbon Formation, Honeywell International, Inc., New York, NY, USA, 2004.

[10] R. F. Handschuh, "High temperature Erosion of plasmasprayed Yttria-stabilized zirconia in a simulated turbine environment," Tech. Rep., American Institute of Aeronautics and Astronautics, Nashville, Tenn, USA, 1985.

[11] R. W. Bruce, "Development of $1232^{\circ} \mathrm{C}\left(2250^{\circ} \mathrm{F}\right)$ erosion and impact tests for thermal barrier coatings," Tribology Transactions, vol. 41, no. 4, pp. 399-410, 1998.

[12] G. D. Roberts, R. T. Bhatt, P.J. Bonacuse et al., "A status of NASA rotorcraft research," type NASA/TP-2009-215369, NASA, 2009.

[13] K. Senesh and V. Babu, "Numerical simulation of subsonic and supersonic jets," in Proceedings of the 11th AIAA/CEAS Aeroacoustics Conference (26th AIAA Aeroacoustics Conference), pp. 3699-3711, AIAA, Monterey, Calif, USA, March 2005, AIAA 2005-3095.

[14] ANSYS FLUENT 6.3 User's Guide, 2006.

[15] D. C. Wilcox, Turbulence Modeling for CFD, DCW Industries, 2nd edition, 2000.

[16] S. A. Morsi and A. J. Alexander, "An investigation of particle trajectories in two-phase flow systems," The Journal of Fluid Mechanics, vol. 55, pp. 193-208, 1972.

[17] R. Clift, J. Grace, and M. E. Weber, Bubbles, Drops, and Particles, Dover, New York, NY, USA, 1978.

[18] R. Swar, "Particle erosion of gas turbine thermal barrier coatings," in Aerospace Engineering and Engineering Mechanics, University of Cincinnati, Cincinnati, Ohio, USA, 2009.

[19] A. Hamed, Y. D. Jun, and J. J. Yeuan, "Particle dynamics simulations in inlet separator with an experimentally based bounce model," Journal of Propulsion and Power, vol. 11, no. 2, pp. 230-235, 1995.

[20] R. A. Miller, M. A. Kuczmarski, and D. Zhu, Burner Rig with an Unattached Duct for Evaluating the Erosion Resistance of Thermal Barrier Coatings, NASA/TM-2011-217008, 2011.

[21] D. Zhu, R. A. Miller, and M. A. Kuczmarski, "Development and life prediction of erosion resistant turbine low conductivity thermal barrier coatings," in Proceedings of the AHS International 65th Annual Forum, pp. 1088-1094, NASA, May 2009.

[22] R. C. Dykhuizen and M. F. Smith, "Gas dynamic principles of cold spray," Journal of Thermal Spray Technology, vol. 7, no. 2, pp. 205-212, 1998.

[23] F. F. Abraham, "Functional dependence of drag coefficient of a sphere on reynolds number," Physics of Fluids, vol. 13, no. 8, pp. 2194-2195, 1970.

[24] F. P. Incropera and D. P. DeWitt, Introduction to Heat Transfer, John Wiley and Sons, New York, NY, USA, 3rd edition, 1996.

[25] S. Whitaker, "Forced convection heat transfer correlations for flow in pipes, past flat plates, single cylinders, single spheres, and for flow in packed beds and tube bundles," AIChE Journal, vol. 18, no. 2, pp. 361-371, 1972. 
[26] J. P. Holman, Heat Transfer, McGraw-Hill, New York, NY, USA, 8th edition, 1997.

[27] ASTM G76 - 07, Standard Test Method for Conducting Erosion Tests by Solid Particle Impingement Using Gas Jet, 2007. 

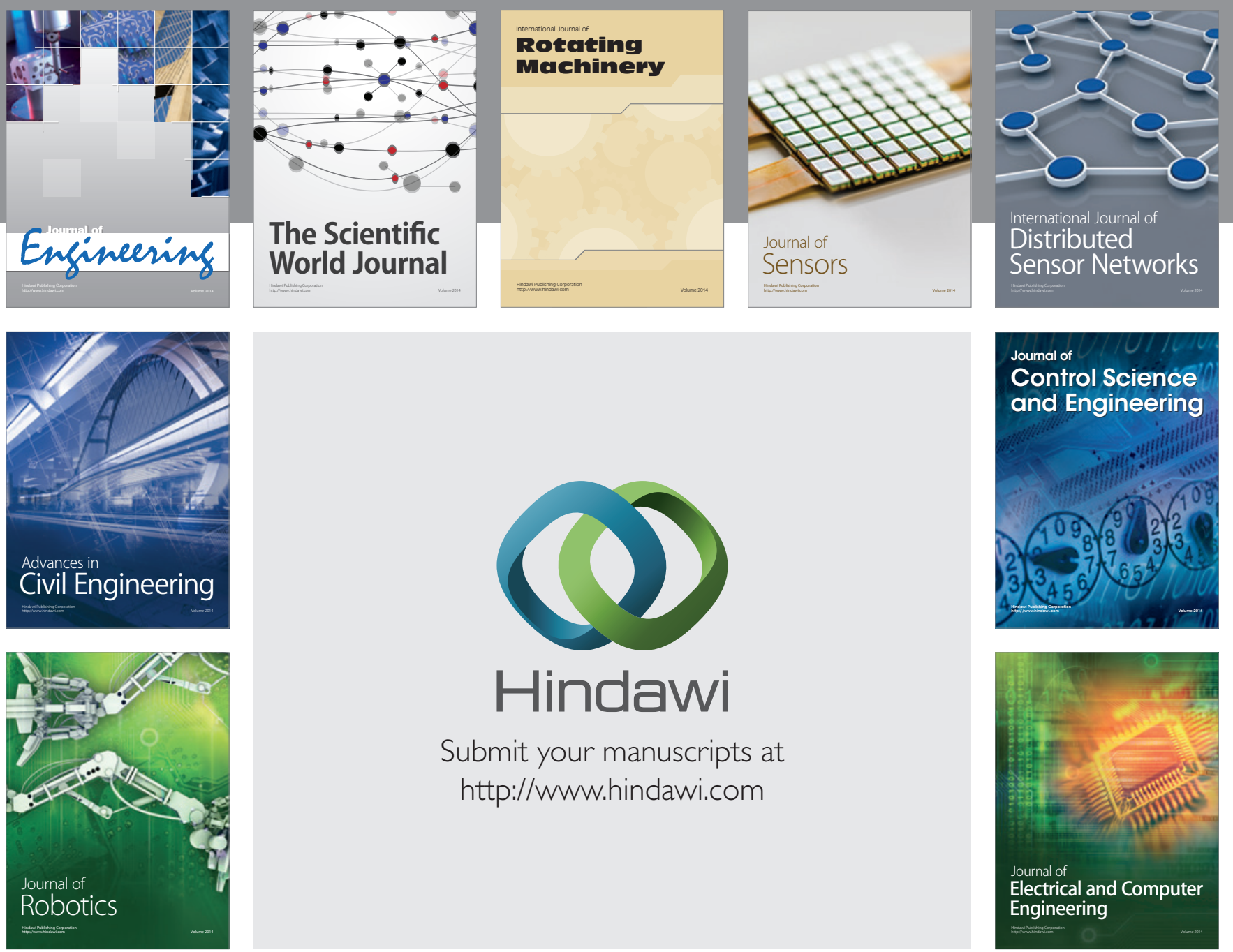

Submit your manuscripts at

http://www.hindawi.com
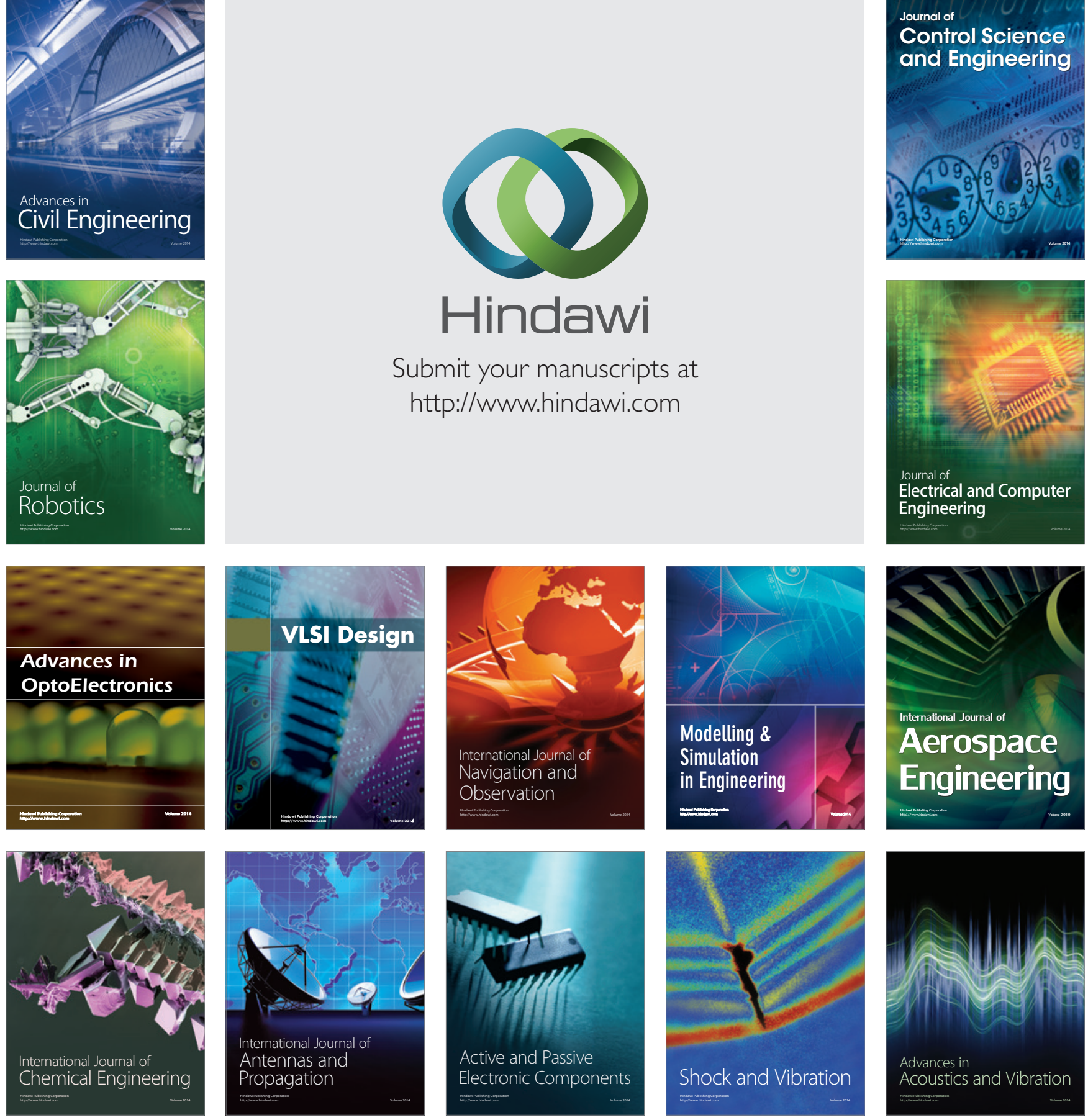